\title{
Expression of Glypican-3 (GPC3) in Malignant and Non-malignant Human Breast Tissues
}

Lilian Castillo ${ }^{1, \circ}$, María Amparo Lago Huvelle ${ }^{1,}$, André Fujita $^{2}$, Aline Ramos Maia Lobba ${ }^{3}$, Rocío Tascón $^{1,}{ }^{\circ}$, Tatiene Romera Garcia ${ }^{3}$, Eduardo Armanasco ${ }^{4}$, Fabio Bagnoli ${ }^{5}$, Vilmar Marques de Oliveira $^{5}$, Maria Antonieta Longo Galvão ${ }^{6}$, Wagner Ricardo Montor ${ }^{7}$, Maria Cleide Sogayar ${ }^{3,8}$, Elisa Bal de Kier Joffé ${ }^{1, \circ}$, Lydia Puricelli ${ }^{1,{ }^{\circ}}$, Leticia Labriola ${ }^{8}$ and María Giselle Peters ${ }^{1, *,}$

${ }^{1}$ Research Area, Institute of Oncology "Angel H. Roffo", University of Buenos Aires. Buenos Aires, Argentina

${ }^{2}$ Department of Computer Science, Institute of Mathematics and Statistics, University of São Paulo. São Paulo, Brazil

${ }^{3}$ NUCEL/NETCEM, School of Medicine, University of São Paulo. São Paulo, Brazil

${ }^{4}$ Surgery Department, Institute of Oncology "Angel H. Roffo", University of Buenos Aires. Buenos Aires, Argentina

${ }^{5}$ Mastology Clinics, Santa Casa de São Paulo Medical School. São Paulo, Brazil

${ }^{6}$ Pathology Department, Santa Casa de São Paulo Medical School. São Paulo, Brazil

${ }^{7}$ Department of Physiological Sciences, Santa Casa de São Paulo Medical School. São Paulo, Brazil

${ }^{8}$ Biochemistry Department-Chemistry Institute, University of São Paulo. São Paulo, Brazil

${ }^{\circ}$ Member of the National Council of Scientific and Technical Research (CONICET)

\begin{abstract}
Specific reports have linked GPC3 with cancer. Its usefulness as a marker has been proved for hepatocarcinoma, melanoma and ovary carcinoma. However, there are no studies analyzing GPC3 usefulness as a biomarker in mammary tumors. The aim of this work was to analyze GPC3 expression in breast tissues and to determine whether it might be useful as a biomarker in breast cancer patients. Expression level of GPC3 mRNA in Brazilian and Argentine human breast tumor $(n=121)$ and peritumoral "normal" tissue $(n=77)$ samples was analyzed using qRT-PCR. GPC3 protein expression was analyzed from 69 breast cancer and 10 peritumoral samples using IHC. Statistical analyses were done to evaluate the clinical-pathological significance of GPC3 expression. We found that Brazilian and Argentine populations are statistically different regarding GPC3 mRNA expression. In Argentine patients a lower GPC3 mRNA expression was found in tumors as compared to peritumoral tissues. No association was found between GPC3 mRNA and protein expression and the clinical-pathological parameters. The Kaplan-Meier curves suggested that elevated levels of GPC3 mRNA are associated with relapse. Our results indicate differential expression of GPC3 in mammary tumors in comparasion to normal breast tissues. They also suggest the potential role of GPC 3 as a biomarker and the importance of deepening the study.
\end{abstract}

Keywords: Biomarker, breast cancer, Glypican-3, metastasis, primary tumor, prognosis.

\section{INTRODUCTION}

Breast cancer is the disease with a major impact on global health [1], with metastasis remaining the main cause of death. Currently, prognostic indicators such as tumor size, lymph node involvement and hormone receptor status, are used to identify patients at high-risk of developing metastasis. However, these parameters are not always accurate. To detect and monitor cancer and determine the most likely prognosis, it is necessary to identify specific molecular markers.

*Address correspondence to this author at the Research Area, Institute of Oncology "Angel H. Roffo". Av. San Martin 5481 (C1417DTB). Buenos Aires, Argentina; Tel: +541145047884; Fax: +541145802811;

E-mails: mpeters@fmed.uba.ar; mgpeters@hotmail.com
Glypican-3 (GPC3), a heparan sulphate proteoglycan [2], is expressed in human embryonic tissues [3] but it disappears from most adult tissues except for mammary gland among others. Several reports have linked GPC3 with cancer [2]. GPC3 overexpression has been shown in Wilms' tumor [4], hepatocellular carcinoma (HCC) [5], and in yolk sac tumor and clear cell ovarian carcinoma [6]. Regarding mammary gland, we have reported that ectopic GPC3 expression in LM3 (a breast mammary murine GPC3 negative metastatic cell line) was able to inhibit invasion and metastasis [7]. We have determined that GPC3 plays a role in almost all steps of the metastasis cascade by inducing mesenchymal-epithelialtransition (MET), suggesting its role as a metastasis suppressor [8]. Although the GPC3 signaling mechanism is unclear, we found that murine GPC3-reexpressing cells 
Table 1. Features of the two populations studied by qRT-PCR.

\begin{tabular}{|c|c|c|c|}
\hline Origin & $\mathbf{N}$ & $\begin{array}{l}\text { Age (years) } \\
\text { Md (range) }\end{array}$ & $\begin{array}{c}\text { DFS time (months) } \\
\text { Md (range) }\end{array}$ \\
\hline $\begin{array}{c}\text { Argentina } \\
\text { Stage I } \\
\text { Stage IIA } \\
\text { Stage IIB } \\
\text { Stage IIIA } \\
\text { Stage IIIB } \\
\text { Stage IV } \\
\text { ND }\end{array}$ & $\begin{array}{c}49 \\
17 \\
12 \\
7 \\
6 \\
2 \\
3 \\
2\end{array}$ & $\begin{array}{c}63(45-90) \\
73(45-92) \\
59.5(47-89) \\
61.5(43-91) \\
55.5(33-78) \\
62(47-83)\end{array}$ & $\begin{array}{c}39(6-60) \\
25.5(4-60) \\
36.5(16-60) \\
23.5(3-60) \\
23.5(15-32) \\
13(8-44)\end{array}$ \\
\hline $\begin{array}{c}\text { Brazil } \\
\text { Stage I } \\
\text { Stage IIA } \\
\text { Stage IIB } \\
\text { Stage IIIA } \\
\text { Stage IIIB } \\
\text { Stage IV } \\
\text { ND }\end{array}$ & $\begin{array}{c}72 \\
11 \\
13 \\
9 \\
10 \\
5 \\
1 \\
23\end{array}$ & $\begin{array}{c}59(55-73) \\
64(51-82) \\
61(37-93) \\
55(32-69) \\
48.5(44-72) \\
44\end{array}$ & $\begin{array}{c}9(9-24) \\
11(4-27) \\
16(5-34) \\
11(4-29) \\
14(6-23) \\
19\end{array}$ \\
\hline
\end{tabular}

ND: not determined

display an inhibition of the canonical Wnt signaling as well as an activation of the non-canonical PCP pathway [9]. We also demonstrated that GPC3 inhibits the PI3K/Akt pathway and stimulates the p38MAPK cascade [10].

We hypothesize that GPC3 would be valuable as a marker of breast disease progression. The usefulness of GPC3 as a marker has been proved for HCCs [5], melanoma [11] and ovary carcinoma [6]. Herein, we have undertaken a novel study aiming at identifying breast cancer patients at high risk of relapse by employing the GPC3 expression pattern in primary tumors. We examined GPC3 expression, at mRNA and protein levels, in breast tumor and peritumoral "normal" tissue samples from Argentine and Brazilian patients. We compared GPC3 expression between both populations and between peritumoral and tumor samples. We also investigated whether GPC3 expression was associated with clinical-pathological, as well as with Ki67, estrogen receptor (ER), progesterone receptor (PR) and HER-2 status, based on immunohistochemistry studies. More importantly, we assessed the value of GPC3 as a possible marker to predict relapse.

\section{MATERIALS AND METHODS}

\section{Study Population}

For the prospective analysis at mRNA level, we collected breast cancer and peritumoral "normal" tissues from patients who had undergone surgical treatment (49 patients from Argentina and 72 patients from Brazil), following the Common Minimum Technical Standards and Protocols from the IARC. Tissue samples were pre-cooled and maintained at $-80^{\circ} \mathrm{C}$. In addition, pieces of samples were fixed and embedded in paraffin for histologically analysis. Table $\mathbf{1}$ shows the features of the studied population.

For the retrospective study at protein level, 69 paraffinembedded breast tumors, as well as 10 peritumoral samples, were obtained from Argentine patients. The features of the population are summarized in Table 2.

Samples eligible for the studies came from patients that met all the following inclusion criteria: female gender, born in Argentina or Brazil, over 21 years old, with operable primary breast carcinoma histologically confirmed according to the tumor-node-metastasis (TNM) system of the American Joint Committee on Cancer/Union Internationale Contre le Cancer (AJCC/UICC), without any previous systemic treatment. Patients' data was obtained by review of the medical charts.

The Ethics Committees of the Institute of Oncology "Angel H. Roffo" (Argentina) and the Santa Casa de Misericordia (Brazil) approved this protocol. The study conforms to The Code of Ethics of the World Medical Association (Declaration of Helsinki). Written informed consent was obtained from each subject.

\section{Analysis of GPC3 Expression by Quantitative Real Time PCR (qRT-PCR)}

\subsection{RNA Extraction and cDNA Synthesis}

Total RNA was extracted from peritumoral "normal" and tumor breast samples, employing TRIzol (Invitrogen Life 
Table 2. Features of the Argentine population studied by IHC.

\begin{tabular}{|c|c|c|c|}
\hline Breast Tumor & n & $\begin{array}{c}\text { Age (Years) } \\
\text { Md (Range) }\end{array}$ & $\begin{array}{c}\text { DFS Time (Months) } \\
\text { Md (Range) }\end{array}$ \\
\hline \hline Non-malignant & 20 & $46.0(22-65)$ & $56.0(3-60)$ \\
\hline Malignant & 49 & & $52.0(16-60)$ \\
\hline Stage I & 12 & $59.0(42-81)$ & $55.0(37-89)$ \\
\hline Stage IIA & 20 & $55.0(34-66)$ & $5-60)$ \\
\hline Stage IIB & 17 & 56.5 \\
\hline
\end{tabular}

DFS: Disease-free survival time

Technologies, Carlsbad-CA-USA) following to the manufacturer's instructions. The quality and integrity of the RNA were confirmed by agarose gel electrophoresis and Gel Green staining (Biotium, San Francisco-CA-USA).

The cDNA was prepared from $1 \mu \mathrm{g}$ of RNA treated with 10 Units of DNase I (Invitrogen Life Technologies, Carlsbad-CA-USA) by using the iScript cDNA synthesis kit (Bio-Rad Life Science, Hercules-CA-USA) according to the manufacturer's protocol. The reaction conditions were: 5 minutes at $25^{\circ} \mathrm{C}, 30$ minutes at $55^{\circ} \mathrm{C}$ and 5 minutes at $95^{\circ} \mathrm{C}$. The cDNA was treated with 1 Unit of RNase $\mathrm{H}$ (GE Healthcare, Little Chalfont-Buckinghamshire-UK).

\section{2. $q R T-P C R$ Reaction}

qRT-PCR amplification was performed using a thermocycler/detector Real Time C1000 CFX96 (Bio-Rad, Hercules-CA-USA) and SYBR Green Master Mix. We used GPC3 forward (5'-GACGCCACCTGTCACCAAGT-3') and reverse (5'-AAACTCCCGTGCCAGGATC-3') primers. Gene expression was normalized relative to Glyceraldehyde3-phosphate dehydrogenase (GAPDH) (Forward: 5'-ACCCACTCCTCCACCTTTGA-3' and Reverse: 5'-ACGAATTTGGCTACAGCAACAG-3').

The PCR reaction was completed in a volume of $12 \mu 1$, consisting of $3 \mu \mathrm{l}$ cDNA (1:3), $6 \mu \mathrm{l} 2 \mathrm{X}$ SYBR Green Master Mix and $3 \mu \mathrm{l}$ forward and reverse primers at $600 \mathrm{nM}$ for GPC3 and $200 \mathrm{nM}$ for GAPDH. The reaction conditions were: 1 cycle of 2 minutes at $50^{\circ} \mathrm{C}$ and 10 minutes at $95^{\circ} \mathrm{C}$, followed by 40 cycles of 15 seconds at $95^{\circ} \mathrm{C}$ and 1 minute at $60^{\circ} \mathrm{C}$. The melting program was performed at $65^{\circ} \mathrm{C}-95^{\circ} \mathrm{C}$ with a heating rate of $0.5^{\circ} \mathrm{C}$ per 15 seconds. Spectral data were captured and analyzed by using CFX Manager ${ }^{\mathrm{TM}}$ Software (Bio-Rad, Hercules-CA-USA). All samples were run in triplicate.

\section{Analysis of GPC3 Expression by Immunohisto Chemistry (IHC)}

Formalin-fixed, paraffin-embedded peritumoral "normal" and tumor breast tissue sections were cut at a thickness of 5 $\mu \mathrm{m}$. Dewaxed sections in $0.01 \mathrm{M}$ citrate buffer $(\mathrm{pH}$ 6.1) were treated three times at $90^{\circ} \mathrm{C}$ for 5 minutes. Endogenous peroxidase activity was blocked with $0.3 \%$ hydrogen peroxide in methanol for 15 minutes, and non-specific immunoglobulin binding was blocked by incubation with
$10 \%$ normal serum for 10 minutes. The sections were incubated overnight at $4^{\circ} \mathrm{C}$ with the primary antibody against human GPC3 $(20 \mu \mathrm{l} / \mathrm{ml}$, clone IG12; kindly provided by Dr. Filmus). Antibodies against Ki67 (clone 30-9) and HER-2 (clone 4B5) (Dako, Demark), ER (clone SP-1) and PR (clone 1E2) (Leica Biosystems, Germany) were employed in the Ventana Benchmark Instrument. The sections were rinsed and incubated for 30 minutes with biotinylated secondary antibodies $(1: 500$, either anti mouse or anti rabbit, Vector Laboratories, Burlingame-CA-USA). The TSA ${ }^{\mathrm{TM}}$ kit (Perkin Elmer, Irvine-CA-USA) was used to amplify the GPC3 signal, following the manufacturer's instructions. The slides were revealed by employing the Vectastain ABC Universal kit (Vector Laboratories, Burlingame-CA-USA) and the 3,3'diaminobenzidine chromogen $(7 \%)$ plus $3 \% \mathrm{H}_{2} \mathrm{O}_{2}$ in PBS. The slides were counterstained with Meyer's hematoxylin.

\section{Statistical Analysis}

For qRT-PCR, we applied $2^{\text {-DeltaCt }}$ equation to establish the relative GPC3 expression (GPC3/GAPDH). We used the Mann-Whitney and Wilcoxon tests to contrast the equality of the Argentine and Brazilian populations. Patients were classified as having a high expression of GPC3 or a low expression of GPC3, with the $25^{\text {th }}$ percentile for mRNA expression of the tumor samples as the cut-off value.

For IHC, the expression of the antigens was scored according to the number of cells with positive bright brownish staining. We used an Allred score (0-8) for hormonal receptors (ER and PR). The levels of HER-2 were scored as $0 /$ Negative $(\leq 10 \%$ of labeled cells, membrane incomplete and negative/weak intensity), 1/Negative ( $>10 \%$ of labeled cells, membrane incomplete and weak intensity), 2/Positive (10-30\% of labeled cells, membrane complete and weak/intense intensity) and 3/Positive ( $>30 \%$ of labeled cells, membrane complete and intense intensity). For Ki67, those samples with more than $14 \%$ of labeled cells were scored as positive. The GPC3 labeling index was calculated following this scale: $\leq 10 \%$ of labeled cells: Negative; $>10 \%$ of labeled cells: Positive.

GPC3 expression (at protein and mRNA levels) was analyzed in a bivariate manner with clinical-pathological covariates through Chi-Square test. The Kaplan-Meier method was used to estimate the time to recurrence and progression, and differences were assessed by using a logrank test. We considered disease-free survival (DFS) to the 


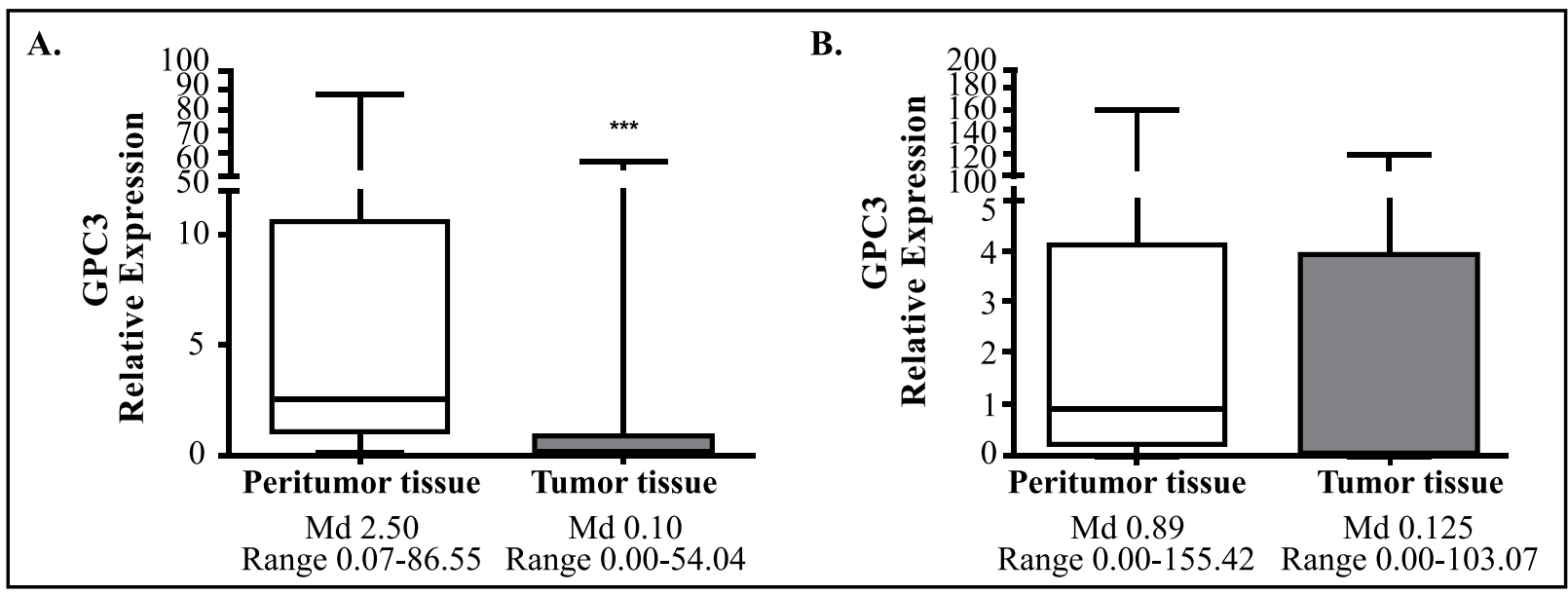

Fig. (1). GPC3 relative expression as measured by qRT-PCR, in tumor and peritumoral "normal" tissues. GPC3 mRNA expression was evaluated in 49 tumor and 24 peritumoral samples from Argentina (A) and in 72 tumor and 53 peritumoral samples from Brazil (B) by qRTPCR. Expression levels were normalized against GAPDH. The boxes represent Md [Rg], and error bars show the standard deviation (SD). a$\mathrm{U}$ Mann-Whitney= 203.00; W Wilcoxon= 1428.00; Z= -4.525; $p$-value= 0.000; b- U Mann-Whitney= 1704.00; W Wilcoxon= 4332.00; $\mathrm{Z}=-1.02 ; p$-value $=0.308$.

time elapsed between surgery and relapse or between surgery and the last visit to hospital for patients who did not relapse.

Statistical analysis was performed by using SPSS 16.0 (IBM Co., Armonk-NY-USA), and a $p$-value<0.05 was considered statistically significant.

\section{RESULTS}

\section{1- Expression of GPC3 by qRT-PCR: Association with Clinical-Pathological Data and DFS Time}

We analyzed the expression of GPC3 at mRNA level in both breast cancer $(n=121)$ and peritumoral "normal" $(n=77)$ samples from Argentine and Brazilian patients. We found that the GPC3 relative expression in tumor samples from Brazil and Argentina is statistically different (U MannWhitney= 1364.500; W Wilcoxon= 2571.500; $Z=-2.208$; $p$-value $=0.027)$. Therefore, they were treated as two independent populations.

As shown in Fig. (1A), for Argentine population we analyzed GPC3 expression in 49 tumor and 24 peritumoral "normal" samples, determining that the expression of GPC3 in tumor samples was lower than that in the peritumoral "normal" ones ( $p$-value<0.0001, Mann-Whitney and Wilcoxon tests). On the other hand, the same trend was obtained from 72 tumor and 53 peritumoral "normal" samples from Brazilian population (Fig. 1B).

We also studied paired samples, namely tumor and normal tissues from the same patient. We defined dissimilar those samples where GPC3/GAPDH levels differed by at least $20 \%$ between tumor and peritumoral tissues. In Argentine population, we found that 18/22 (86.4\%) patients presented a lower GPC3 relative level in tumor than in the corresponding peritumoral sample, while one patient presented the same expression in both tissues (Fig. 2A). Meanwhile, in Brazilian population we found a lower GPC3 relative level in tumor tissue in $21 / 50(42 \%)$ patients, while no differences were found in 9/50 (18\%) (Fig. 2B).
The optimal reference value to differentiate patients from controls was the $25^{\text {th }}$ percentile of GPC3 tumor expression. Therefore, we established that those samples with GPC3 expression higher than the $25^{\text {th }}$ percentile $(0.0100$ for the Argentine population and 0.0225 for the Brazilian one) would be considered as GPC3 positive. We determined that $72 \%$ of tumor tissues from Argentina and 69\% of tumor samples from Brazil express GPC3 mRNA. Meanwhile, $100 \%$ of Argentine peritumoral samples and $91 \%$ of Brazilian ones were GPC3 positive.

No association was found between GPC3 relative levels in tumor tissues and the different clinical-pathological parameters (Chi-square test), either for the Argentine population (Table 3) or the Brazilian one (Table 4). Moreover, GPC3 expression was not associated with triple negative tumors in either population (data not shown). These data suggest the independence of GPC3 expression.

Evaluation of the DFS time was carried out in a group of 44 breast cancer Argentine patients with a 3 to 60 months follow-up period. The Kaplan-Meier survival curves showed a borderline significant association between GPC3 expression and DFS (Log rank test, $p$-value=0.06) (Fig. 3). Surprisingly, positive GPC3 expression was associated with earlier relapse. It is important to highlight that no negative GPC3 tumor-harboring patient relapsed during the 5-years follow-up period.

\section{2- Expression of GPC3 by IHC: Association with Clinical-Pathological Data and DFS Time}

We studied GPC3 protein expression in the Argentine breast tumor patients' samples by immunostaining. As Fig. (4) shows, GPC3 expression was low and mainly restricted to the membrane. Among the 69 breast tumor samples examined, GPC3 was detected in 12 cases $(17.4 \%)$. As shown in Table 5, only $10 \%$ of non-malignant tumors showed positive staining for GPC3, while the $20.4 \%$ 

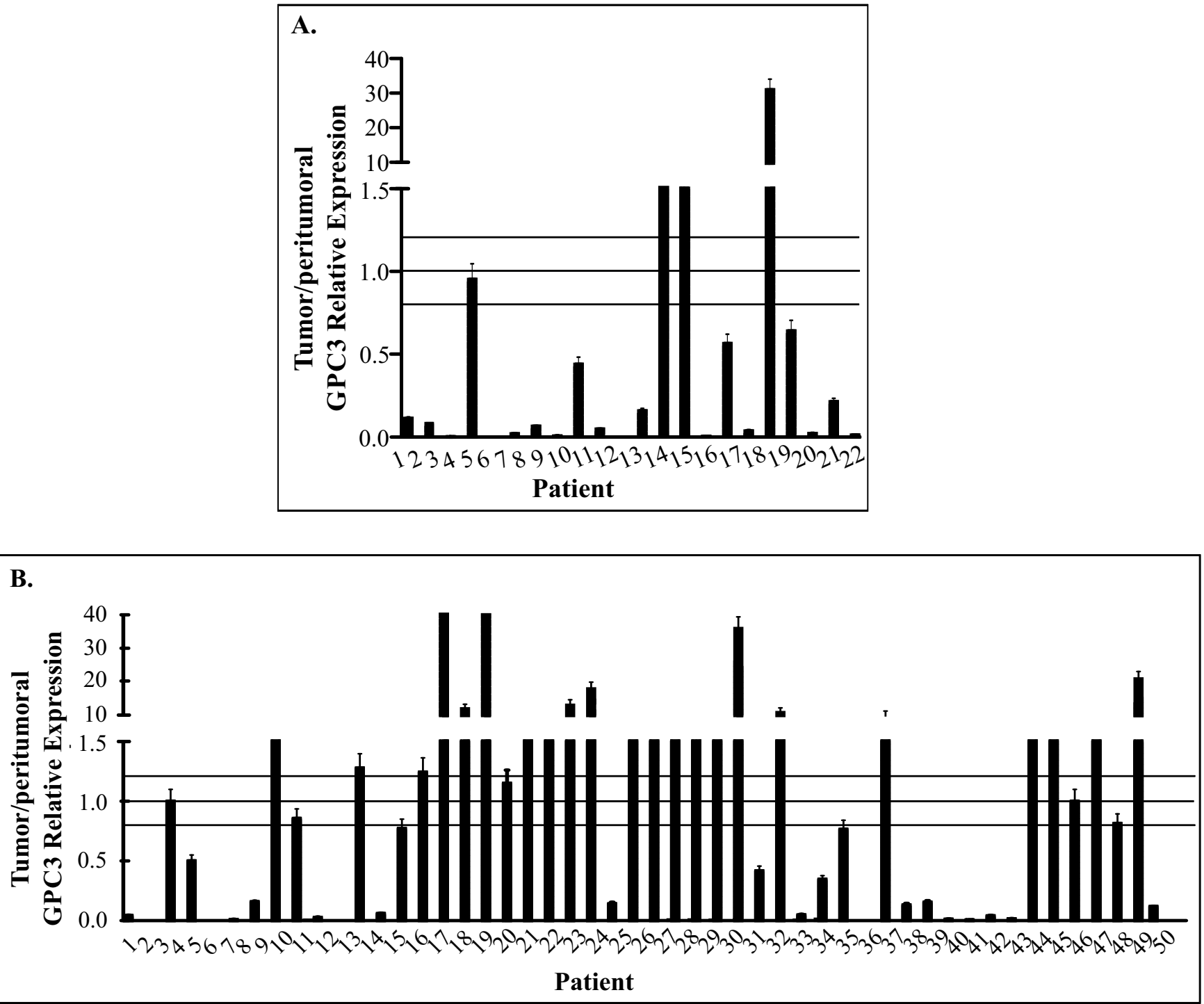

Fig. (2). GPC3 relative expression as measured by qRT-PCR, in tumor versus peritumoral "normal" tissues from de same patient. GPC3 mRNA expression was evaluated in tumor and peritumoral "normal" tissues from the same patient (22 patients from Argentina (A) and in 50 patients from Brazil (B)) by qPCR and normalized against GAPDH. The bars represent average Tumor/Normal ratios of GPC3 mRNA expression in paired breast cancer. Error bars represent the standard deviation of the mean (SD).

Table 3. Clinical-pathological characteristics of Argentine patients and their association with GPC3 expression at mRNA level.

\begin{tabular}{|c|c|c|c|c|}
\hline Features & Positive/Negative & Positive/Total (\%) & Chi-square value & $p$ \\
\hline \multicolumn{5}{|c|}{ Age (years) } \\
\hline$\leq 50$ & $6 / 3$ & 66.7 & & \\
\hline $51-70$ & $16 / 6$ & 72.7 & 0.828 & 0.843 \\
\hline$>70$ & $12 / 4$ & 75.0 & & \\
\hline \multicolumn{5}{|c|}{ Status } \\
\hline Premenopausic & $6 / 2$ & 75.0 & & \\
\hline Perimenopausic & $5 / 1$ & 83.3 & 0.666 & 0.717 \\
\hline Postmenopausic & $21 / 10$ & 67.7 & & \\
\hline
\end{tabular}


Table 3. contd....

\begin{tabular}{|c|c|c|c|c|}
\hline Features & Positive/Negative & Positive/Total (\%) & Chi-square value & $p$ \\
\hline \multicolumn{5}{|c|}{ Stage } \\
\hline$I A$ & $13 / 4$ & 76.5 & \multirow{6}{*}{2.124} & \multirow{6}{*}{0.832} \\
\hline$I I A$ & $7 / 4$ & 63.6 & & \\
\hline$I I B$ & $5 / 3$ & 62.5 & & \\
\hline IIIA & $5 / 1$ & 83.3 & & \\
\hline$I I I B$ & $2 / 0$ & 100.0 & & \\
\hline$I V$ & $2 / 1$ & 66.7 & & \\
\hline \multicolumn{5}{|c|}{ Tumor Size (cm) } \\
\hline$\leq 2.0$ & $11 / 9$ & 55.0 & \multirow{3}{*}{4.550} & \multirow{3}{*}{0.103} \\
\hline $2.1-5.0$ & $16 / 3$ & 84.2 & & \\
\hline$>5.0$ & $5 / 1$ & 83.3 & & \\
\hline \multicolumn{5}{|c|}{ Lymph Nodes } \\
\hline Non-metastatic & $24 / 9$ & 72.7 & & \\
\hline Metastatic & $10 / 4$ & 71.4 & 0.08 & 0.927 \\
\hline \multicolumn{5}{|c|}{ Histologic Grade } \\
\hline$I$ & $1 / 0$ & 100.0 & \multirow{3}{*}{0.431} & \multirow{3}{*}{0.806} \\
\hline$I I$ & $9 / 4$ & 69.2 & & \\
\hline$I I I-I V$ & $20 / 8$ & 71.4 & & \\
\hline \multicolumn{5}{|c|}{ Nuclear Grade } \\
\hline$I$ & $4 / 0$ & 100.0 & \multirow{3}{*}{3.602} & \multirow{3}{*}{0.165} \\
\hline II & $14 / 3$ & 82.4 & & \\
\hline III & $15 / 9$ & 62.5 & & \\
\hline \multicolumn{5}{|c|}{ Histological Type } \\
\hline Lobular & $7 / 1$ & 87.5 & \multirow{3}{*}{1.118} & \multirow{3}{*}{0.572} \\
\hline Ductal & $25 / 11$ & 69.4 & & \\
\hline Others & $2 / 1$ & 66.7 & & \\
\hline \multicolumn{5}{|c|}{ Mitotic Index } \\
\hline$\leq 5$ & $8 / 2$ & 80.0 & \multirow{4}{*}{2.520} & \multirow{4}{*}{0.472} \\
\hline $6-10$ & $10 / 4$ & 71.4 & & \\
\hline $11-20$ & $9 / 6$ & 60.0 & & \\
\hline$>20$ & $3 / 0$ & 100.0 & & \\
\hline \multicolumn{5}{|c|}{ Estrogen Receptor } \\
\hline Negative & $5 / 0$ & 100.0 & & \\
\hline Positive & $29 / 11$ & 72.5 & 1.820 & 0.177 \\
\hline \multicolumn{5}{|c|}{ Progesterone Receptor } \\
\hline Negative & $9 / 1$ & 90.0 & & \\
\hline Positive & $25 / 10$ & 71.4 & 1.452 & 0.228 \\
\hline
\end{tabular}


Table 3. contd....

\begin{tabular}{|c|c|c|c|c|}
\hline Features & Positive/Negative & Positive/Total (\%) & Chi-square value & $p$ \\
\hline \multicolumn{5}{|c|}{ HER-2 } \\
\hline Positive & $4 / 1$ & 80.0 & 0.06 & 0.806 \\
\hline \multicolumn{5}{|c|}{ Ki67 } \\
\hline Positive & $7 / 0$ & 100.0 & 0.674 & 0.412 \\
\hline
\end{tabular}

NS, Chi-square test.

Table 4. Clinical-pathological characteristics of Brazilian patients and their association with GPC3 expression at mRNA level.

\begin{tabular}{|c|c|c|c|c|}
\hline Features & Positive/Negative & Positive/Total (\%) & Chi-square value & $p$ \\
\hline \multicolumn{5}{|c|}{ Age (years) } \\
\hline$\leq 50$ & $6 / 1$ & 85.7 & & \\
\hline $51-70$ & $17 / 4$ & 81.0 & 1.351 & 0.509 \\
\hline$>70$ & $6 / 0$ & 100.0 & & \\
\hline \multicolumn{5}{|c|}{ Status } \\
\hline Premenopausic & $7 / 3$ & 70.0 & & \\
\hline Perimenopausic & $2 / 1$ & 66.7 & 4.090 & 0.129 \\
\hline Postmenopausic & $19 / 1$ & 95.0 & & \\
\hline \multicolumn{5}{|c|}{ Stage } \\
\hline$I A$ & $5 / 2$ & 71.42 & & \\
\hline$I I A$ & $7 / 2$ & 77.78 & & \\
\hline$I I B$ & $7 / 2$ & 77.78 & 6.208 & 0.287 \\
\hline IIIA & $7 / 1$ & 87.50 & & \\
\hline$I I I B$ & $1 / 3$ & 25.0 & & \\
\hline$I V$ & $1 / 0$ & 100.0 & & \\
\hline \multicolumn{5}{|c|}{ Tumor Size (cm) } \\
\hline$\leq 2.0$ & $9 / 4$ & 69.2 & & \\
\hline $2.1-5.0$ & $14 / 6$ & 70.0 & 2.059 & 0.357 \\
\hline$>5.0$ & $5 / 0$ & 100.0 & & \\
\hline \multicolumn{5}{|c|}{ Lymph Nodes } \\
\hline Non-metastatic & $17 / 6$ & 73.9 & & \\
\hline Metastatic & $11 / 3$ & 78.6 & 0.103 & 0.749 \\
\hline \multicolumn{5}{|c|}{ Histologic Grade } \\
\hline$I$ & $0 / 1$ & 0.0 & & \\
\hline II & $15 / 2$ & 88.2 & 5.790 & 0.055 \\
\hline$I I I-I V$ & $13 / 2$ & 86.7 & & \\
\hline
\end{tabular}


Table 4. contd....

\begin{tabular}{|c|c|c|c|c|}
\hline Features & Positive/Negative & Positive/Total (\%) & Chi-square value & $p$ \\
\hline \multicolumn{5}{|c|}{ Nuclear Grade } \\
\hline$I I$ & $1 / 1$ & 50.0 & 0 & 1 \\
\hline III & $1 / 1$ & 50.0 & & \\
\hline Lobular & $1 / 1$ & 50 & & \\
\hline Ductal & $25 / 4$ & 86.2 & 2.288 & 0.319 \\
\hline Others & $2 / 0$ & 100.0 & & \\
\hline \multicolumn{5}{|c|}{ Estrogen Receptor } \\
\hline \multicolumn{5}{|c|}{ Progesterone Receptor } \\
\hline Negative & $10 / 1$ & 90.9 & & \\
\hline Positive & $18 / 6$ & 75.0 & 1.193 & 0.275 \\
\hline \multicolumn{5}{|c|}{ HER-2 } \\
\hline Negative & $30 / 10$ & 75.0 & & \\
\hline Positive & $9 / 0$ & 100.0 & 2.319 & 0.314 \\
\hline \multicolumn{5}{|c|}{ Ki67 } \\
\hline Negative & $10 / 2$ & 88.3 & & \\
\hline
\end{tabular}

NS, Chi-square test.

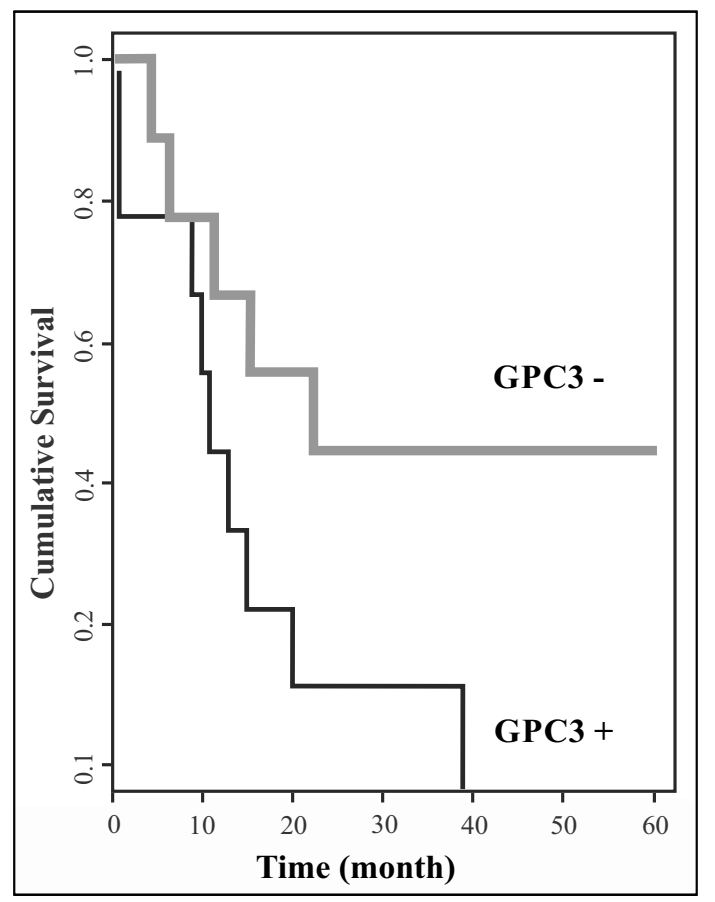

Fig. (3). Kaplan-Meier disease-free survival (DFS) curve according to qRT-PCR GPC3 expression. Cases were stratified into negative GPC3 mRNA expression and positive GPC3 mRNA expression. The graph shows the Kaplan-Meier curve of DFS stratified by GPC3 mRNA expression. Log rank test $=2.89, p$-value $=0.06$ 


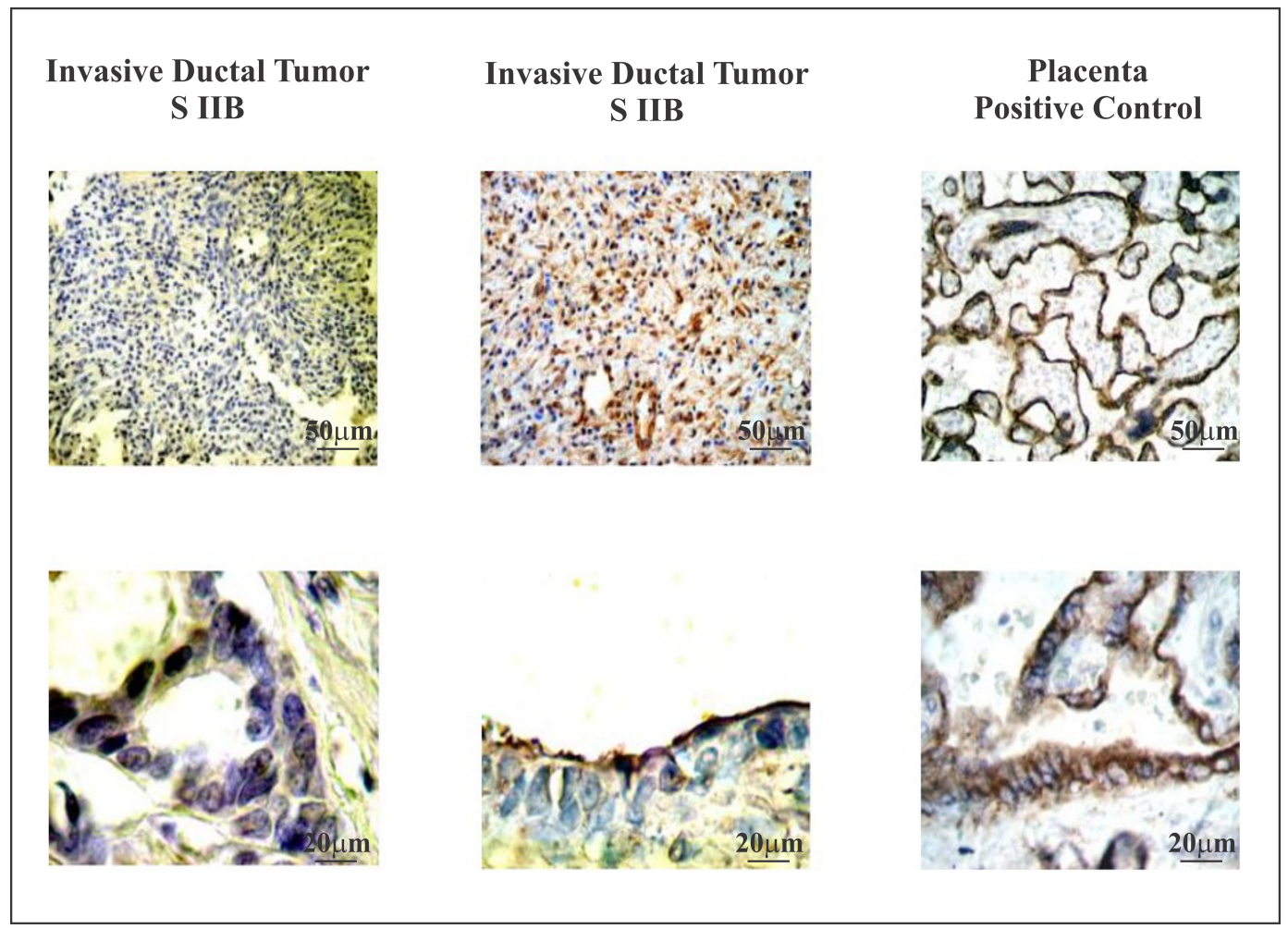

Fig. (4). Immunohistochemical staining pattern for GPC3 in breast cancer. GPC3 expression was evaluating at protein level by IHQ, in 69 tumor samples from Argentine. Representative images of GPC3-positive and GPC3-negative tumors are shown. Invasive ductal tumor, stage II, GPC3-negative (a); Invasive ductal tumor, stage II, GPC3-positive (b) Placenta GPC3-Positive Control.

Table 5. Immunohistochemical GPC3 expression in Argentine breast tumor samples.

\begin{tabular}{|c|c|c|c|c|}
\hline & Non-malignant Tumor \\
& $\mathbf{n}(\%)$ & $\begin{array}{c}\text { Malignant } \\
\text { Tumor } \\
\mathbf{n}(\%)\end{array}$ & $\begin{array}{c}\text { Total } \\
\mathbf{n}(\%)\end{array}$ & Chi-square value \\
\hline \hline GPC3 & $2(10.0)$ & $10(20.4)$ & $12(17.4)$ & \\
Positive & $18(90.0)$ & $39(79.6)$ & $57(82.6)$ & 1.01 \\
Negative & & & 0.25 \\
\hline
\end{tabular}

NS, Chi-square test

Table 6. Clinical-pathological characteristics of Argentine patients and their association with GPC3 expression at protein level.

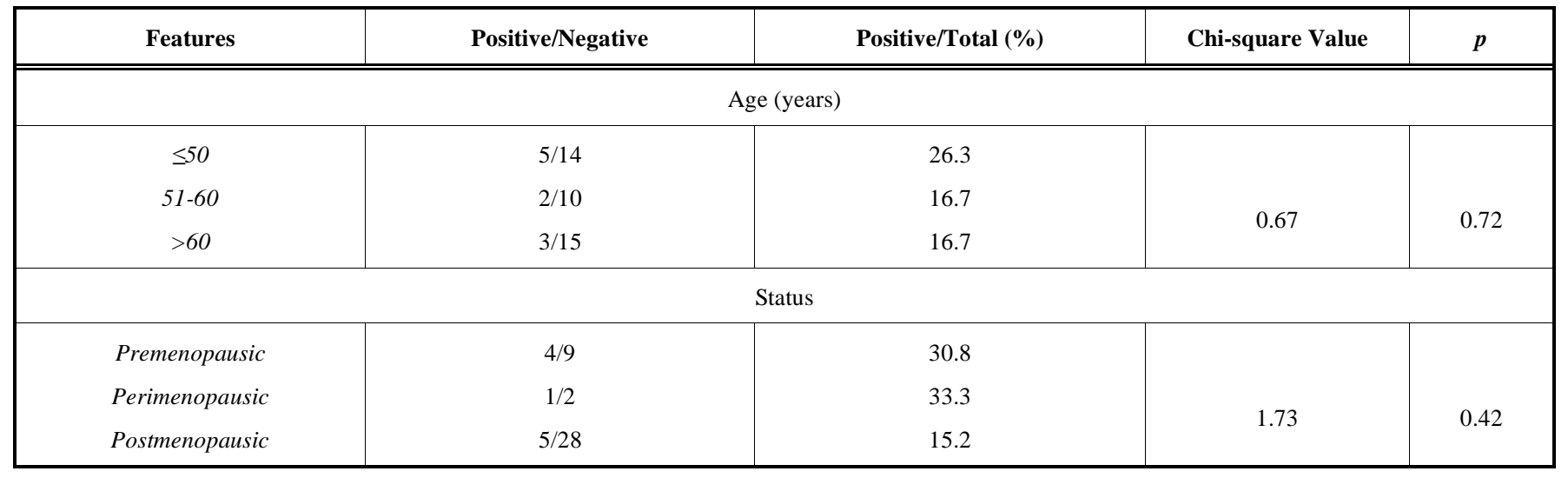




\begin{tabular}{|c|c|c|c|c|}
\hline Features & Positive/Negative & Positive/Total (\%) & Chi-square value & $p$ \\
\hline \multicolumn{5}{|c|}{ Stage } \\
\hline$I A$ & $4 / 8$ & 33.3 & \multirow{3}{*}{6.208} & \multirow{3}{*}{0.287} \\
\hline IIA & $2 / 17$ & 10.5 & & \\
\hline$I I B$ & $4 / 14$ & 22.2 & & \\
\hline \multicolumn{5}{|c|}{ Tumor Size (cm) } \\
\hline$\leq 1.0$ & $0 / 4$ & 0.0 & \multirow{3}{*}{1.35} & \multirow{3}{*}{0.72} \\
\hline $1.1-2.0$ & $4 / 15$ & 21.1 & & \\
\hline$>2.1$ & $6 / 20$ & 30.0 & & \\
\hline \multicolumn{5}{|c|}{ Lymph Nodes + } \\
\hline 0 & $6 / 14$ & 30.0 & \multirow{3}{*}{2.48} & \multirow{3}{*}{0.29} \\
\hline $1-3$ & $2 / 18$ & 10.0 & & \\
\hline$>4$ & $2 / 7$ & 22.2 & & \\
\hline \multicolumn{5}{|c|}{ Histologic Grade } \\
\hline$I$ & $0 / 2$ & 0.0 & \multirow{3}{*}{2.02} & \multirow{3}{*}{0.57} \\
\hline II & $2 / 14$ & 12.5 & & \\
\hline$I I I-I V$ & $6 / 15$ & 33.3 & & \\
\hline \multicolumn{5}{|c|}{ Nuclear Grade } \\
\hline$I$ & $1 / 4$ & 20.0 & \multirow{3}{*}{2.34} & \multirow{3}{*}{0.31} \\
\hline$I I$ & $3 / 21$ & 12.5 & & \\
\hline III & $6 / 13$ & 31.6 & & \\
\hline \multicolumn{5}{|c|}{ Histological Type } \\
\hline Lobular & $2 / 7$ & 22.2 & \multirow{3}{*}{0.38} & \multirow{3}{*}{0.83} \\
\hline Ductal & $7 / 30$ & 18.9 & & \\
\hline Others & $1 / 2$ & 33.3 & & \\
\hline \multicolumn{5}{|c|}{ Estrogen Receptor } \\
\hline Negative & $3 / 8$ & 27.3 & & \\
\hline Positive & $6 / 31$ & 16.2 & 0.68 & 0.33 \\
\hline
\end{tabular}

NS, Chi-square test

of malignant tumors did it. Unexpectedly, the peritumoral "normal" tissue did not show positive staining (data not shown).

GPC3 immunoreactivity, when categorized into negative versus positive expression, was not associated with the tested clinical-pathological parameters (Table 6). Furthermore, no association was found between GPC3 and the expression of Ki67 or HER-2 (data not shown).

The evaluation of the DFS time was carried out in a group of 27 breast cancer patients. No association was found between GPC3 expression at protein level and relapse (Fig. 5).

\section{DISCUSSION}

Here we demonstrated GPC3 expression in human breast cancer both at mRNA and protein levels. To our knowledge, no previous studies were performed at both levels of expression, in a large cohort of patients with this disease. It has been shown that while normal breast tissues are GPC3 positive, the expression of GPC3 is silenced in human breast cancer [12]. This analysis was conducted over a decade ago by in situ hybridization, employing 12 breast cancer samples. It is noteworthy that although the authors concluded that GPC3 was silenced by hypermethylation of its promoter in breast tumors, 5 of the 12 samples analyzed had detectable 


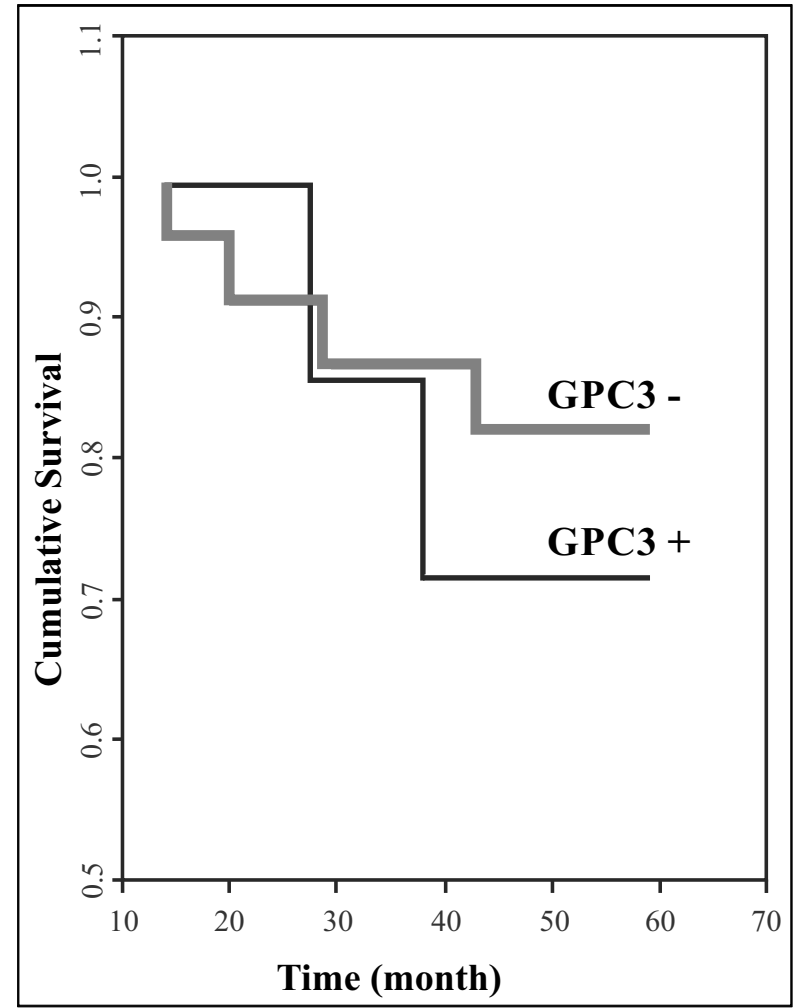

Fig. (5). Kaplan-Meier disease-free survival (DFS) curve according to IHC GPC3 expression. Cases were stratified into negative GPC3 protein immunostaining and positive GPC3 protein immunostaining. The graph shows the Kaplan-Meier curve of DFS stratified by GPC3 protein expression. Log rank test $=1.64, p$-value $=0.2$.

expression of GPC3. In contrast, using microarray technology comprising 4,387 tissue samples from 139 tumor categories and 36 non-neoplastic and pre-neoplastic tissue types, another group concluded that normal breast tissues are negative for GPC3 [13]. The immunohistochemical expression of GPC3 was detected in 3/27 (11\%) of tubular breast carcinomas, $4 / 48(8 \%)$ of invasive ductal breast carcinomas, and $9 / 46(19.5 \%)$ of invasive lobular breast carcinomas.

Here, we analyzed GPC3 expression at mRNA level in biopsies from Argentine and Brazilian breast cancer patients. We found that $72 \%$ of tumor tissues from Argentina and $69 \%$ of tumor samples from Brazil express GPC3 mRNA. Meanwhile, $100 \%$ of Argentine peritumoral "normal" samples and $91 \%$ of Brazilian ones were GPC3 mRNA positive. Paired breast cancer lesions and adjacent noncancerous tissues were found to have different expression of GPC3 mRNA levels in Argentine patients, with cancer lesions displaying relatively lower expression of this glypican.

We also analyzed GPC3 expression at protein level by IHC, in 69 breast tumors, as well as in 10 peritumoral "normal" samples from Argentine patients. The number of samples with positive labeling was low (10\% for nonmalignant tumors and $20 \%$ for carcinomas). In opposition to Xiang et al. [12] and in agreement with Baumhoer et al. [13], we did not find positive labeling for GPC3 in "normal" adjacent mammary tissues.
We hypothesize that the discrepancy between our IHC and qRT-PCR analyzes may be due to differences in the sensitivity of the procedure employed. Inconsistencies between IHC and qRT-PCR have been previously reported [14]. There are limitations inherent to the reliability and reproducibility of IHC techniques. We suggest that qRTPCR would be a most appropriate method to assess GPC3 levels in breast tissues. This indication is even more applicable when we take into account that glypicans may be secreted into the medium [15]. In addition, it is established that GPC3 is composed of two subunits that are linked by disulfide bonds [16]. If GPC3 protein analysis is run under reducing conditions, the two GPC3 subunits will be separated, and an antibody directed against the $\mathrm{NH} 2$ terminus would not yield any positive staining (since the $\mathrm{COOH}$-terminal fragment is the one which remains anchored to the membrane). Finally, it is not possible to rule out the existence of a differential translational control, characterized by the differential utilization of pre-existing mRNAs, in normal and tumor breast tissues. Changes either in the pool size or the phosphorylation state of translation initiation factors (eIFs) leads to general variations in translation. Other mechanisms include alterations in translation elongation or poly(A) tail-length modulation [17]. Recently, it has been proposed that GPC3 overexpression in HCCs is linked to the down-regulation of an specific microRNAs [18]. Therefore, we hypothesize that normal breast tissue may express detectable levels of GPC3 messenger, although it is not subsequently translated into protein. 
In summary, although GPC3 would be silenced in breast cancer due to promoter hypermethylation [12], our study showed GPC3 expression at both protein and mRNA levels in breast biopsies. Therefore, silencing of GPC 3 could be a characteristic event in certain subgroups of breast cancers.

We also analyzed whether GPC3 is associated with any of the known clinical-pathological parameters, as well as with cell proliferation (Ki67), with the expression of HER-2 and hormonal receptors (ER and PR), and with triple negative tumor phenotype. We found that neither GPC3 mRNA nor protein expression in Argentine and Brazilian samples is associated with any of the established prognosis parameters. This suggests that GPC3 might be an independent biomarker. In order to determine whether GPC3 expression has impact on DFS, we plotted the Kaplan-Meier curves. Surprisingly, we found evidence that GPC 3 would be indicative of poor prognosis in breast cancer patients. These findings encourage evaluating GPC3 expression in a larger cohort of breast cancer patient in order to determine its actual value as predictor for prognosis and survival.

It is known that animal models have provided a breakthrough in cancer research, but the results obtained in animals can not always be directly extrapolated to human. Since we have previously shown in a murine model that GPC3 acts as a metastasis suppressor [7-10], a comprehensive analysis of the molecular mechanism of GPC3 role in the development and progression of human breast cancer is eagerly awaited. We do believe that the progress in GPC3 signaling research will provide new insights to attack targets involved in metastasis, offering unique opportunities for the development of "intelligent" therapeutics, which will lead to novel alternatives to treat breast cancer patients.

In conclusion, our results indicate differential expression of GPC3 in mammary tumors in compare to normal breast tissues. They also point GPC3 as a possible prognostic indicator in breast cancer patients, and suggest the importance of deepen the study.

\section{CONFLICT OF INTEREST}

All authors would like to confirm the inexistence of any financial and personal relationships with other people or organizations that could inappropriately influence our work.

\section{ACKNOWLEDGEMENTS}

We would like to give our thanks to Dr. Stella Maris Ranuncolo for her invaluable assistance in preparing this manuscript. The work was supported by grant from FONCyT (PICT 2008-1387-Préstamo BID 1728/OC-AR), Ministry of Science and Technical Argentina.

\section{REFERENCES}

[1] Smith AW, Alfano CM, Reeve BB, et al. Race/ethnicity, physical activity, and quality of life in breast cancer survivors. Cancer Epidemiol Biomarkers Prev 2009; 18: 656-63.

[2] Filmus J. Glypicans in growth control and cancer. Glycobiology 2001; 11: 19R-23R.

[3] Iglesias BV, Centeno G, Pascuccelli H, et al. Expression pattern of glypican-3 (GPC3) during human embryonic and fetal development. Histol Histopathol 2008; 23: 1333-40.

[4] Toretsky JA, Zitomersky NL, Eskenazi AE, et al. Glypican-3 expression in Wilms tumor and hepatoblastoma. J Pediatr Hematol Oncol 2001; 23: 496-9.

[5] Capurro M, Wanless IR, Sherman M, et al. Glypican-3: a novel serum and histochemical marker for hepatocellular carcinoma. Gastroenterology 2003; 125: 89-97.

[6] Maeda D, Ota S, Takazawa Y, et al. Glypican-3 expression in clear cell adenocarcinoma of the ovary. Mod Pathol 2009; 22: 824-32.

[7] Peters MG, Farias E, Colombo L, Filmus J, Puricelli L, Bal de Kier Joffe E. Inhibition of invasion and metastasis by glypican-3 in a syngeneic breast cancer model. Breast Cancer Res Treat 2003; 80: 221-32.

[8] Buchanan C, Lago MAH, Peters MG. Metastasis suppressors: basic and translational advances. Curr Pharm Biotechnol 2011; 12: 194860.

[9] Stigliano I, Puricelli L, Filmus J, Sogayar MC, Bal de Kier Joffe E, Peters MG. Glypican-3 regulates migration, adhesion and actin cytoskeleton organization in mammary tumor cells through Wnt signaling modulation. Breast Cancer Res Treat 2009; 114: 251-62.

[10] Buchanan C, Stigliano I, Garay-Malpartida HM, et al. Glypican-3 reexpression regulates apoptosis in murine adenocarcinoma mammary cells modulating PI3K/Akt and p38MAPK signaling pathways. Breast Cancer Res Treat 2010; 119: 559-74.

[11] Nakatsura T, Kageshita T, Ito S, et al. Identification of glypican-3 as a novel tumor marker for melanoma. Clin Cancer Res 2004; 10: 6612-21.

[12] Xiang YY, Ladeda V, Filmus J. Glypican-3 expression is silenced in human breast cancer. Oncogene 2001; 20: 7408-12.

[13] Baumhoer D, Tornillo L, Stadlmann S, Roncalli M, Diamantis EK Terracciano LM. Glypican 3 expression in human nonneoplastic, preneoplastic, and neoplastic tissues: a tissue microarray analysis of 4,387 tissue samples. Am J Clin Pathol 2008; 129: 899-906.

[14] Oda M, Arihiro K, Kataoka T, Osaki A, Asahara T, Ohdan H. Comparison of immunohistochemistry assays and real-time reverse transcription-polymerase chain reaction for analyzing hormone receptor status in human breast carcinoma. Pathol Int 2010; 60(4): 305-15.

[15] Watanabe K, Yamada H, Yamaguchi Y. K-glypican: a novel GPIanchored heparan sulfate proteoglycan that is highly expressed in developing brain and kidney. J Cell Biol 1995; 130: 1207-18.

[16] De Cat B, Muyldermans SY, Coomans C, et al. Processing by proprotein convertases is required for glypican-3 modulation of cell survival, Wnt signaling, and gastrulation movements. J Cell Biol 2003; 163: 625-35.

[17] Garcia-Sanz JA, Mikulits W, Livingstone A, Lefkovits I, Mullner EW. Translational control: a general mechanism for gene regulation during T cell activation. FASEB J 1998; 12: 299-306.

[18] Maurel M, Jalvy S, Ladeiro Y, et al. A functional screening identifies five microRNAs controlling glypican-3: role of miR1271 down-regulation in hepatocellular carcinoma. Hepatology 2013; 57(1): 195-204. 